\title{
Occurrence of the Sri Lankan Flying Snake, Chrysopelea cf. taprobanica (Smith 1943) in Tamil Nadu, India
}

\author{
Surya Narayanan ${ }^{1}$, Naveen Joseph ${ }^{2}$, Ranjith Kumar ${ }^{3}$, and Arul Vengatesan ${ }^{4}$ \\ ${ }^{1}$ Ashoka Trust for Research in Ecology and the Environment, Royal Enclave, Sriramapura, Jakkur Post, Bangalore, Karnataka, India (surya.narayanan@atree.org) \\ ${ }^{2}$ National Troopers for Conservation of Nature, Palayamkottai, Tirunelveli, Tamil Nadu, India \\ ${ }^{3}$ Aathu Palam, Coimbatore, Tamil Nadu, India \\ ${ }^{4}$ Bank Nagar, Vellore, Tamil Nadu, India
}

"F lying Snakes" in the genus Chrysopelea are arboreal colubrids. The genus comprises five species (Uetz and Hošek 2013) of which two, C. ornata (Shaw 1802) and $C$. taprobanica Smith 1943, have been recorded in India. The Golden Flying Snake (C. ornata) ranges through northern India and much of southeastern Asia to the Philippines, with a disjunct population recognized at the subspecific level in Sri Lanka. Chrysopelea taprobanica was considered a color variant of $C$. ornata until recognized as a distinct species by Smith (1943) and was believed to be endemic to Sri Lanka (Taylor 1950; Deraniyagala 1955; Pyron et al. 2013). However, Guptha et al. (2015) recently documented the presence of the species in the Seshachalam Biosphere Reserve in the Eastern Ghats of India (Fig. 1). Herein we provide two additional records of $C$. cf. taprobanica, one each from the Western and Eastern Ghats.

At 1530 h on 19 March 2016, R. Kumar rescued a live snake (Fig. 2) from a human habitation in the foothills of the Western Ghats in Kalampalayam, Coimbatore, Tamil Nadu (10.928512N, 76.82129E; elevation $518 \mathrm{~m}$ asl; Fig. 1). The site is within the Nilgiri Biosphere Reserve. Because we suspected that the snake was $C$. taprobanica, we recorded measurements and scale counts before taking voucher photographs and releasing the snake at the site of capture. We counted dorsal scale rows one head length behind the neck, at approximately midbody, and one head length anterior to the vent. We counted ventrals as in Dowling (1951). A comparison (Table 1) with recently recorded (Guptha et al. 2015) and literature data (Smith 1943; Constable 1949) suggests that this individual was C. taprobanica. However, in the absence of molecular data and in light of variation in only one scale character (see below), we conservatively refer to this snake as $C$. cf. taprobanica.

On 14 January 2015, Arul sighted a similar snake (Fig. 3) in an area of riparian and dry deciduous forest in the Javadu Hills of the Eastern Ghats (12.581463N, 78.861228E; ele- vation $657 \mathrm{~m}$ asl; Fig. 1), approximately $125 \mathrm{~km}$ south of the previous record (Guptha et al. 2015). The sighting was

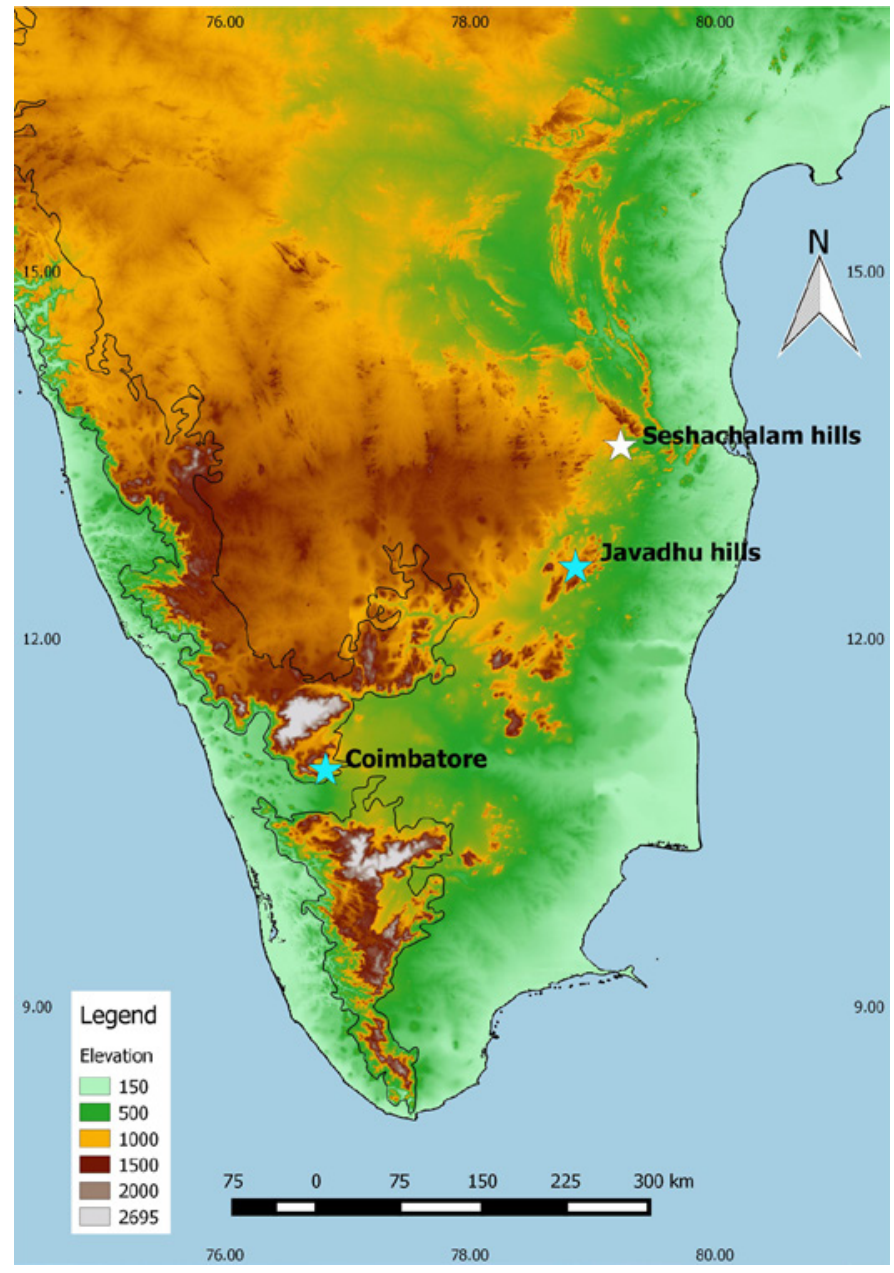

Fig. 1. Known localities for the Sri Lankan Flying Snake (Chrysopelea taprobanica) in India. The previously known location (white star) is in the Seshachalam Biosphere Reserve in the Eastern Ghats (Guptha et al. 2015) and the additional locations (blue stars) reported herein are in the Javadu Hills of the Eastern Ghats and Coimbatore of the Western Ghats. 


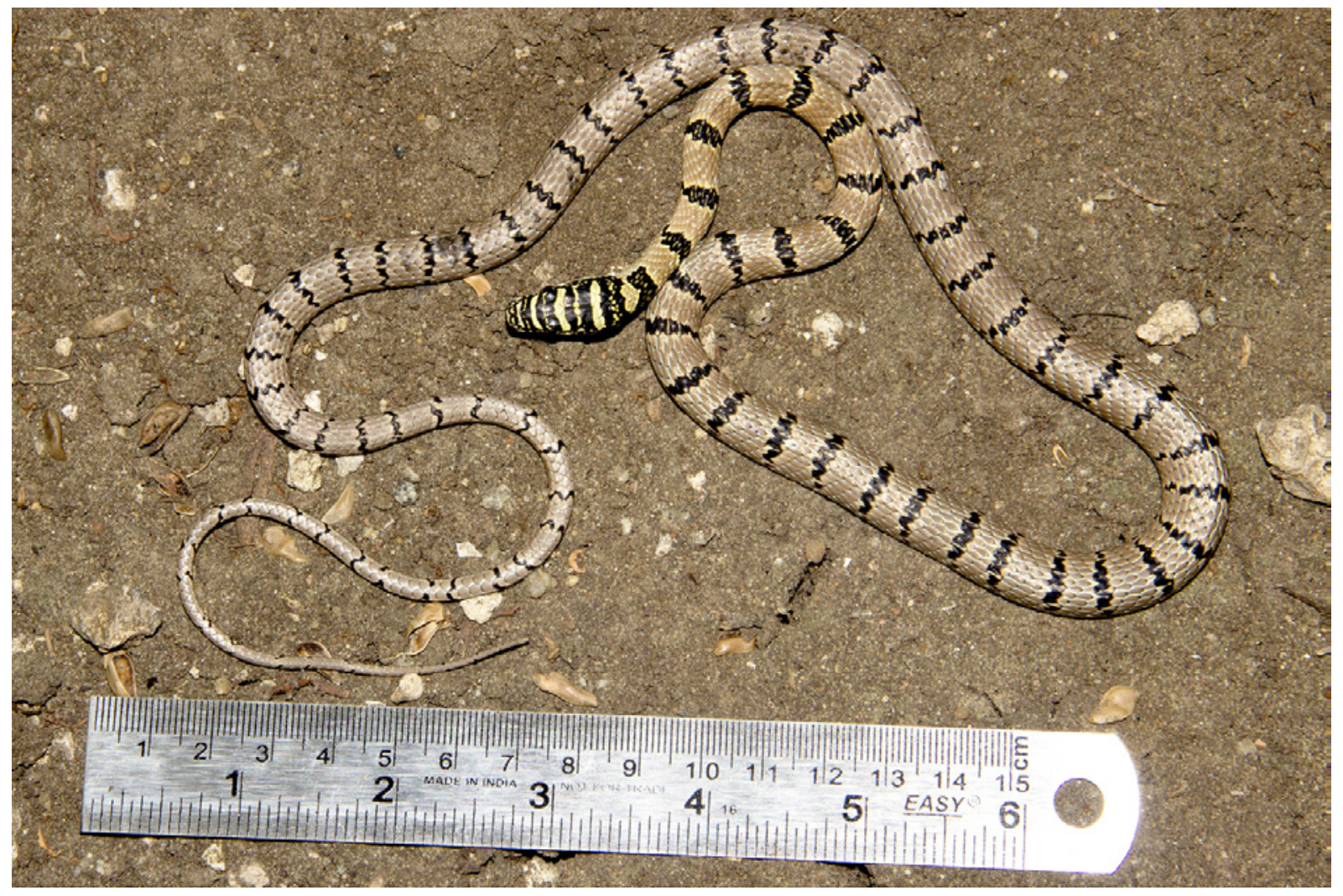

Fig. 2. A Sri Lankan Flying Snake (Chrysopelea cf. taprobanica) rescued from a human habitation in Coimbatore, India. Photograph by Naveen Joseph.

Table 1. Comparison of the snake reported herein (Chrysopelea cf. taprobanica from Coimbatore) and those identified as C. taprobanica and described by Guptha et al. (2015) and Constable (1949).

\begin{tabular}{lccc}
\hline Character & Current work & Gource & Constable (1949) \\
\hline Dorsal scale rows & $17: 17: 13$ & $17: 17: 15$ & 17 \\
\hline Ventrals & 202 & 201 & 208 \\
\hline Subcaudals & 106 & 106 & 120 \\
\hline Supralabials & 9 & 9 & 9 \\
\hline Supralabials entering the eye & 4,5, and 6 & 4,5, and 6 & 4,5 , and 6 \\
\hline Loreals & 1 & 1 & 1 \\
\hline Preoculars & 1 & 1 & 1 \\
\hline Postoculars & 2 & 2 & $2+2$ \\
\hline Temporals & $2+2$ & $2+2$ & - \\
\hline Infralabials & 8 & - & 560 \\
\hline Snout-vent length $(\mathrm{mm})$ & 501 & 589 & 225 \\
\hline Tail length (mm) & 190 & 223 & - \\
\hline Bands on body & 56 & 57 & - \\
\hline Bands on tail & 26 & 14 & Olive with black bands \\
\hline Dorsal color & Olive with black bars & & 2 \\
\hline
\end{tabular}




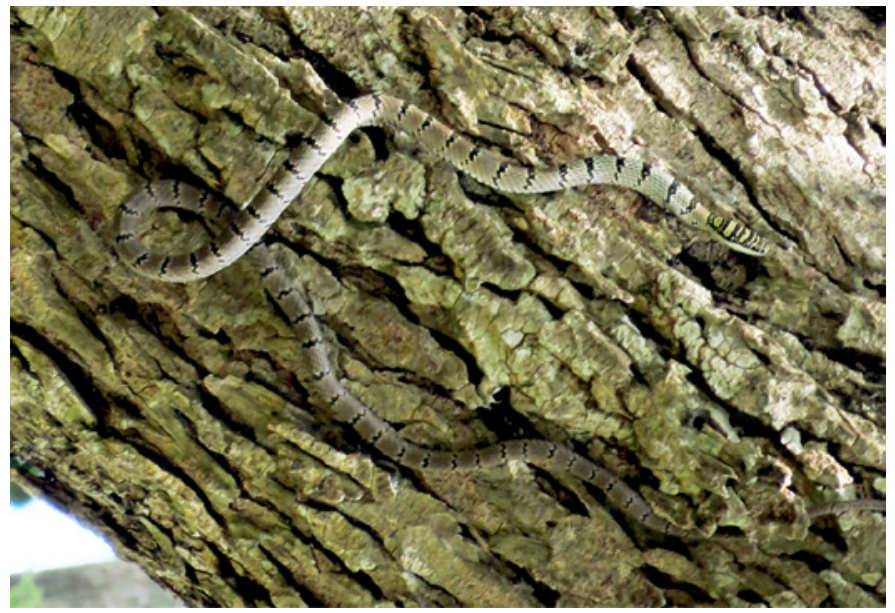

Fig. 3. A Sri Lankan Flying Snake (Chrysopelea cf. taprobanica) encountered in the Javadu Hills, Tamil Nadu, India. Photograph by Arul Vengatesan.

opportunistic, so the snake was not collected and no data were recorded. Consequently, we could not confirm its identity, but color and pattern suggest that it was $C$. cf. taprobanica.

The current record from Coimbatore matches previous descriptions of $C$. taprobanica except for dorsal scale rows of 17:17:13 (vs. 17:17:15) and a divided cloacal scale (vs. undivided; Guptha et al. 2015; Smith 1943 — note that an undivided cloacal was the character Smith used to differentiate C. taprobanica from C. ornata). The snake described herein might be aberrant or the population in the Western Ghats might vary from those found elsewhere. This would have to be determined by examining more samples.

Although Guptha et al. (2015) claimed the first confirmed record of $C$. taprobanica from India, they overlooked earlier records in Constable (1949), who reported the species in "Madras" (present-day Tamil Nadu, Telangana, and Andhra Pradesh). Most recently, Somaweera et al. (2015) revalidated the records of Constable (1949) and others. Three specimens labeled as C. taprobanica were examined, and one in the Naturhistorisches Museum Wien (NMW 27287:34) was confirmed to be $C$. taprobanica. Unfortunately, except for the record in Guptha et al. (2015), we do not know the precise localities for any other specimens. Nevertheless, the two records from Tamil Nadu suggest that the species occupies a broad geographic area; and we suspect that C. taprobanica is widespread in the Eastern Ghats. The new record of C. cf. taprobanica from the Western Ghats further indicates that the distribution includes the Western Ghats. Possible explanations for the apparently broad range of this species in India include: (1) it has always been present but overlooked because it is either rare or cryptic; (2) it has dispersed recently (although this would appear to be unlikely); or (3) its range is expanding due to human mediation (unlikely, but not impossible). More fieldwork will be necessary to resolve questions regarding the taxonomic status of these snakes and to determine the actual status of the species' distribution in India.

\section{Acknowledgements}

We thank Vivek Sharma for insight and Allwin Jesudasan for his comments on an earlier draft of this manuscript. We also thank Deepak Veerapan for suggestions regarding species identification and for encouraging us to write this note. We thank Abhishek Samrat for providing the map.

\section{Literature Cited}

Constable, J.D. 1949. Reptiles from the Indian Peninsula in the Museum of Comparative Zoology. Bulletin of the Museum of Comparative Zoology 103: 59-160.

Deraniyagala, P. 1955. A Colored Atlas of Some Vertebrates from Ceylon. Volume Three: Serpentoid Reptilia. Government Press, Colombo, Sri Lanka.

Dowling, H.G. 1951. A proposed standard system of counting ventrals in snakes. British Journal of Herpetology 1: 97-99.

Guptha, B., N.V.S. Prasad, S.T. Maddock, and V Deepak. 2015. First record of Chrysopelea taprobanica Smith, 1943 (Squamata: Colubridae) from India. Check List 11: 1523.

Smith, M.A. 1943. The Fauna of British India, Ceylon and Burma, Including the Whole of the Indo-Chinese Sub-region. Reptilia and Amphibia. Volume III, Serpentes. Taylor and Francis, London.

Uetz, P. and Hošek, J. (eds.) 2013. The Reptile Database. <http://www.reptiledatabase.org/>.

Pyron, R.A., H.K.D. Kandambi, C.R. Hendry, V. Pushpamal, F.T. Burbrink, and R. Somaweera. 2013. Genus-level phylogeny of snakes reveals the origins of species richness in Sri Lanka. Molecular Phylogenetics and Evolution 66: 969-978.

Somaweera, R., D.L. Pantoja, and V. Deepak. 2015. Forgotten records of Chrysopelea taprobanica Smith, 1943 (Squamata: Colubridae) from India. Zootaxa 3947: 597-600.

Taylor, E.H. 1950. A brief review of Ceylonese snakes. University of Kansas Science Bulletin 33: 519-603. 